Adults' retractions of childhood sexual abuse allegations: High-stakes and the (in)validation of recollection.

$$
\text { James Ost }
$$

Department of Psychology, University of Portsmouth

$$
\text { (in press), Memory }
$$

(Special issue: Theoretical and legal issues regarding autobiographical belief and recollection)

Acknowledgements: I am indebted to Hartmut Blank, Alan Costall, Henry Otgaar, Vasu Reddy and two anonymous reviewers for comments on an earlier draft of this manuscript.

Author note: A version of this paper was presented at the XIth biennial conference of the Society for Applied Research in Memory and Cognition (SARMAC), 24-27 June, 2015, Victoria, BC, Canada. All data and coding supporting this article can be found in the Supplementary Materials available on the journal website. This is the accepted version of the manuscript and not the copy of record. 


\begin{abstract}
Retractors are individuals who have repudiated their earlier claims of having been sexually abused. There has been relatively little research conducted with this population. The growing literature on memory verification strategies and non-believed memories provide a conceptual and empirical lens through which to revisit the accounts of these individuals to try and learn more about the process of making and retracting high-stake, consequential beliefs or recollections about the past. Do people attempt to validate or invalidate beliefs and recollections of such events in the same way as they do for the moderately significant events studied to date? The paper concludes by re-emphasising the social and contextual nature of remembering and argues for the primacy of belief over recollection.
\end{abstract}


“This is about belief, and it's up to me to choose what I want to believe. I don't want to believe that this is the truth" (Linda Furness, in Pendergrast, 1996, p. 360).

In 1986, Patricia Burgus was diagnosed with multiple personality disorder (now dissociative identity disorder). Under the influence of drugs and hypnosis she recollected that she had been part of a satanic cult, had sexually abused her own children, cannibalized people, and had sex with a former US president. Burgus eventually retracted her beliefs and recollections, and filed a lawsuit, claiming that mental health professionals had implanted false memories. In 1997, on the day the case was due to be tried, her family accepted an out of court settlement of over 10 million dollars (Loftus, 1998). Individuals like Burgus, seem to provide clear evidence that "at least some individuals may develop inaccurate memories about past abuse" (Epstein \& Bottoms, 1998, p. 1234). Yet, not all cases involve such extreme and highly improbable claims, and there are obvious limitations in relying on retractors' accounts to formulate theory.

One inevitable problem is that it is almost impossible to satisfactorily establish the 'ground truth'. In addition there are self-presentational biases inherent in reporting about an event (or series of events) that one no longer believes in (Ashmore \& Brown, 2010; Blume 1995; Gudjonsson, 1997; Kassin, 
1997; Ost, Costall \& Bull 2002; Singer, 1997). Yet, as Schooler, Bendiksen and Ambadar (1997) argued:

“... there is simply no principled reason why we should believe individuals when they recover memories but then disbelieve them when they retract them. Nor, for that matter, can we disbelieve recoveries and use retractions as evidence of memory fabrication. Ultimately, the fact that individuals can shift between believing and disbelieving ... illustrates the fundamental uncertainty that surrounds such memories" (p. 258; see also Schacter, Norman \& Koutstaal, 1997).

What is important, psychologically, is to understand how people make sense of such fundamental uncertainties and how they come to endorse and then reject a belief about their past, particularly one that has such far-reaching consequences ${ }^{1}$. The fact that it is difficult (if not impossible) to establish the ground truth, and that there may be self-serving or unconscious biases in presenting events in a certain light (as is the case with almost any claim about one's personal past, e.g., Wilson \& Ross, 2003) should not prevent scientific enquiry. One need not take a firm position on the existence of a deity, for example, in order to propose theories about the psychology of religious experiences (e.g., Hinde, 1999). For example, early attempts to theorise about retractors' experiences drew parallels to related literatures including

\footnotetext{
${ }^{1}$ For work investigating recantations / retractions made by child witnesses, the reader is referred to work by Malloy, Lyon and Quas (2007) and Lyon (2007).
} 
imaginative processes, role enactment (de Rivera, 1998) and false confessions in police interviews (Ost et al., 2002).

Other attempts to characterise retractors' experiences tried to disentangle the issues of belief and recollection (see de Rivera \& Sarbin, 1998). For example Ost (2003), drawing on the work of Sir Frederic Bartlett, argued for the primacy of 'attitudes' (or beliefs) over recall (or recollection). Rather than directly recalling past events, Bartlett argued that people start by making inferences about their current circumstances based on what must have happened in their past ("This and this and this must have occurred in order that my present state should be what it is"; Bartlett, 1932, p. 202, emphasis added). This 'attitude' 2 then guides construction of the past, leading to "the eventual building up of the complete story accompanied by the more and more confident advance in a certain direction" (Bartlett, 1932, pp. 205). Recall is a construction made "largely on the basis of this attitude, and its general effect is that of a justification of the attitude" (Bartlett, 1932, p. 207). This process, Bartlett suggested, was a response to a diverse and constantly changing environment that required "adaptability, fluidity and variety of response" (1932, p. 281). Thus the changing (social) context was a critical determinant of recall and "the immediate situation sets the problems which they [the items 'picked out of schema'] are to help solve" (Bartlett, 1932, p. 297).

\footnotetext{
${ }^{2}$ The concept of 'attitude' is, according to some (e.g., Larsen \& Berntsen, 2000), an overlooked aspect of Bartlett's theory that refers to "an interpretation of [the] event from the particular perspective of the individual" (p. 103).
} 
For Bartlett, then, 'attitude' (or 'belief about the probable constituents') set the stage for recall (or 'recollection'). Furthermore, the social context in which this "constant rationalisation" (p. 207) occurred determined "both the manner and the matter of recall" (p. 244). In other words, the social context determined the 'attitude' (or belief) about the past, which drove memory construction. Unfortunately, Bartlett's important ideas about the adaptive and social nature of remembering, and the distinction between belief and recollection, were largely overlooked ${ }^{3}$ partly because of the way in which he summarised the findings of his own studies (Ost \& Costall, 2002).

It was not until much later that the distinction between memory and belief was formally incorporated into metacognitive models of memory (e.g., Mazzoni \& Kirsch, 2002). These models allowed for dissociations between memory and belief such that individuals could believe events had occurred despite being unable to recollect them, as well as the possibility that individuals could recollect events that they no longer believe happened to them (e.g., Scoboria, Mazzoni, Kirsch \& Relyea, 2004; Mazzoni, Scoboria \& Harvey, 2010). More recently still, researchers have begun to investigate the strategies that people use to verify their memories (Wade \& Garry, 2005; Wade, Nash \& Garry, 2014). These two sets of literature provide frameworks that can be used to revisit retractors' accounts and investigate their experiences of endorsing and

\footnotetext{
${ }^{3}$ See Edwards and Middleton (1987) and Edwards, Potter and Middleton (1992) for an account of remembering that draws on the social aspect of Bartlett's theory.
} 
then rejecting consequential events from their past. It is to these two bodies of research that we now turn.

Verifying memories: In repudiating their earlier recollections, retractors are making claims about whether or not certain events occurred. But what strategies and evidence are they using to make those judgements? Wade and Garry (2005) asked participants to recall a memory that they later found out to be false, as well as to imagine they had developed a false memory from participating in a 'Lost in the mall' type study (e.g., Loftus \& Pickrell, 1995). They then asked participants to articulate the strategies that they had used, or would use, to verify those events. The key finding was that the majority of strategies were either low cost, like asking other people (e.g., family members) or suboptimal, like trying to imagine whether the event had occurred or not (see Garry, Manning, Loftus \& Sherman, 1996). Later work confirmed that participants typically rely more on low cost, rather than reliable, strategies (Wade et al., 2014)4.

In these verification studies, some participants recall (or imagine they had experienced) moderately significant, potentially upsetting, events (e.g., breaking their nose; becoming lost as a child). Wade et al. (2014) noted, "subjects' relative weighting of reliability and cost might shift if the memory

\footnotetext{
${ }^{4}$ In a similar vein, Nash and Takarangi (2011) found that individuals who had experienced alcoholic blackouts were slightly more likely to seek information about events that had occurred during that blackout from someone who was similarly intoxicated at the time, rather than from someone who was sober.
} 
they were verifying was of even greater emotional or personal importance" (p. 33). Retractors' accounts provide one source of data to tentatively address that issue; do people use markedly different sources of evidence when the events they are trying to verify are more consequential (i.e., do they rely on more 'high cost', reliable sources, like physical evidence)? In addition, we can also look at the other side of the coin. What factors were important in leading retractors to withdraw belief in their recollections? To do this, we turn to the literature on non-believed memories.

Nonbelieved memories: In 2002 Mazzoni and Kirsch argued that experiments on 'false' memories could be divided into those that studied autobiographical memory and those that studied autobiographical belief. Scoboria et al. (2004) developed this further and proposed a formal model in which plausibility, belief and memory were presented as nested constructs. In other words, in order to develop a false memory, an individual first needed to believe that the event occurred to him or her. In order to believe that an event occurred, one needed to first believe that the event was plausible and could have happened to him or her. Scoboria et al. (2004) further subdivided plausibility into general plausibility (i.e., something that could happen in principle) and personal plausibility (i.e., something that could happen to me). In that paper they also noted that some $4 \%$ of cases they encountered did not fit neatly into this nested constructs model; these were cases in which people reported that they clearly recollected events that they were sure had not happened. Citing 
the anecdote about Piaget, the famous developmental psychologist, who claimed to vividly remember being abducted as a small child, despite learning that it had never occurred (see Loftus \& Ketcham, 1991) they noted that, "it appears that memories for events which did not occur can continue to carry a strong sense of reality even once those who possess them are certain they did not occur" (Scoboria et al., 2004, p. 793). Mazzoni et al. (2010) provided the first empirical data confirming this possibility (see also Otgaar, Scoboria \& Smeets, 2013). They surveyed 1593 US and UK undergraduates and found that just under $25 \%$ of them reported that they could recollect at least one event that they no longer believed happened, a phenomenon they termed nonbelieved memory (NBM; see Scoboria, Mazzoni \& Boucher, in press, for a review).

Do retractors' accounts of withdrawing belief in their recollections provide evidence for the existence of high stake, non-believed memories for traumatic and personally relevant autobiographical events (Scoboria et al., in press)? In the remainder of this article, memory verification strategies and the notion of non-believed memory (NBM) will be used as a conceptual frame for retractors' experiences. Firstly, comparisons are made between the strategies that people have been shown to use to verify moderately significant events (e.g., Wade et al., 2014), and retractors' reports of coming to believe in or recollect traumatic memories of sexual abuse - is there any evidence that retractors use 'high cost' reliable strategies to verify these life changing beliefs 
or recollections? Secondly, comparisons are drawn between retractors' accounts of the repudiation of their beliefs and recollections and the largest systematic exploration of this issue with naturalistic NBMs in the published literature to date (Scoboria et al., 2015). Are the dynamics of withdrawing belief similar when the events are highly consequential? Thirdly, using the qualitative descriptions of what it was that retractors were actually endorsing and then rejecting, the focus then moves to an examination of how well the two characteristics of nonbelieved memories (the belief in occurrence is attenuated yet the mental representation continues to be experienced as a memory) represent retractors' experiences. To address these questions, the literature on retractors' experiences was re-examined and coded as outlined below.

METHOD

\section{Sources of data}

A literature review was conducted on Google Scholar ${ }^{\mathrm{TM}}$ using the search terms 'retractor', 'memory' and combinations of the two to identify sources that focussed on how retractors came to endorse and then reject beliefs or recollections of abuse. As a result, several articles and chapters (Ashmore \& Brown, 2010; Davis, 2005; de Rivera, 1998; Fetkewicz, Sharma \& Merskey, 2000; Ost et al., 2002; Woodiwiss, 2010) were reviewed but excluded from the 
analysis presented here because, although they refer to retractors, they did not focus explicitly on the process of endorsing and withdrawing belief. Inspecting citations of the remaining studies then identified more recent work. This was not intended as an exhaustive search of every publication that mentioned retractors; rather it served to identify key published work that contained data that could be compared - at least on a conceptual or thematic level - to the findings of Wade et al. (2014) and Scoboria et al. (2015).

The final dataset consisted of three books containing case studies or anecdotal accounts (Goldstein \& Farmer, 1993; Pendergrast, 1996; Maran, 2010), one unpublished thesis containing quotes from a survey (Ost, 2000), and seven articles and chapters containing case studies or summaries of surveys and interviews (de Rivera, 1997; de Rivera, 2000; Lief \& Fetkewicz, 1995; McElroy \& Keck, 1995; Nelson \& Simpson, 1994; Ost et al., 2001; Ost \& Nunkoosing, 2010). Excluding accounts that were clearly from the same person (e.g., an account by Laura Pasley is reported in both Goldstein \& Farmer, 1993 and Pendergrast, 1996) resulted in a nominal sample of 158 retractors. This figure must be interpreted with extreme caution however, as it is almost certain that some of the individuals who served as case studies in Goldstein and Farmer (1993) and Pendergrast (1996) also participated in later surveys and interviews in other published work. Where there was a clear, or likely duplication, cases were only coded once. Furthermore, some studies (e.g., see de Rivera, 2000, p. 381) had already summarised responses from many 
respondents into categories, thus there may originally have been subtleties in those original data (i.e., pre-categorisation) that could not be captured by the current coding scheme. The full range of data coded can be found in the Supplementary Data online.

\section{Coding}

The author conducted all the coding, and the full dataset (and coding scheme) can be found in the Supplementary Materials. The first stage of coding involved reviewing all published accounts and recording verbatim where descriptions were given of sources of evidence that supported the beliefs or recollections about abuse using the categories identified by Wade et al. (2014). The categories were: (1) Searching for physical evidence; (2) Asking another person - family; (3) Asking another person - other; (4) Cognitive techniques; and (5) Searching for additional cues.

The second stage of coding involved recording verbatim where explanations were given regarding the cause(s) of retraction. In NBM terminology, what was it that caused retractors to attenuate belief in their recollections? In almost all of the case studies and anecdotal accounts, such an explanation could be located, although in the survey studies (e.g., Lief \& Fetkewicz, 1995) such information was difficult to extract systematically, as typically only group level data were reported. The subcategories described by Scoboria et 
al. (2015) were used as a guide here. These were: (1) Social feedback; (2) Event plausibility; (3) Alternative attributions; (4) General beliefs regarding memory; (5) Internal memorial characteristics; (6) Notions of self / others; (7) External evidence; (8) Personal motivation; and (9) Other.

The final stage of coding involved a examination of the retractor literature to identify any self-reports of the quality of their initial beliefs and/or recollections. This was more challenging, as detailed accounts like this were not included in the published literature in any systematic fashion (the only exception was found in de Rivera, 2000, p. 381). Nevertheless it was possible to find key exemplars that matched almost all possible combinations of belief and recollection, not just recollections where belief was attenuated (i.e., nonbelieved memories). These exemplars are simply presented here as prima facie evidence for the existence of such categories, and no claims are (or can be) made about their prevalence.

\section{RESULTS AND DISCUSSION}

What sources of evidence did retractors use to 'verify' their beliefs or recollections (or what sources of evidence were they exposed to)? 
Recall that, in Wade and Garry (2005) and Wade et al. (2014), participants suggested strategies that they would use (or had used) to verify their recollections. No similar data exist in the retractors literature.

As shown in Table 1, there were almost no clear examples of retractors using explicit 'strategies' to try and establish whether they had been abused or not. Far more common was that retractors reported being exposed to various sources of evidence. For example, where Wade et al.'s (2014) participants report 'searching for physical evidence' to validate their recollections, retractors report 'being presented with physical / psychological evidence' to validate the allegation that they had been sexually abused. Where participants in Wade et al. (2014) report using cognitive techniques, retractors report having been subjected to 'memory recovery techniques' and so on. Nevertheless, as Table 1 shows, at least at a conceptual level there appears to be a reasonable degree of overlap between the sources of evidence (e.g., physical evidence, other people, cognitive strategies, search for additional cues) reported by Wade et al.'s (2014) participants and retractors' retrospective accounts of why they came to endorse their beliefs or recollections of abuse.

As shown in Table 2, analysis of retractors' reports found no evidence that any of them searched for objective evidence that the abuse had occurred. Interestingly, however, allegedly 'objective' physical $(n=4)$ and psychological evidence $(n=4)$ was occasionally offered to them in the form of interpretations 
of 'body memories' or flashbacks ${ }^{5}$. Of course, being 'offered' evidence is very different from actively 'seeking' evidence. The latter is indeed a strategy that one might employ where the former is not. Nevertheless, these two categories were compared here as they both speak to the way in which external evidence was used to support or attenuate beliefs and recollections. There was also limited evidence that retractors spoke to other family members about their beliefs or recollections. However, retractors' reports suggest that people other than family members were key in convincing them that they had been sexually abused $(n=9)$. In the majority of cases $(n=6)$ that person was a therapist or counsellor. Only one of Wade et al.'s strategies (thinking back to an event in order to recall more information) appeared to be used by retractors. Indeed a few retractors $(n=4)$ reported trying this ("Spent a week trying to remember"; Goldstein \& Farmer, 1993, p. 288). A larger proportion of retractors $(n=13)$ reported being the subject of memory recovery techniques (e.g., "He [therapist] kept insisting that I close my eyes and picture my abuse"; Pendergrast, 1996, p. 388). Wade et al.'s (2014) final category concerns cases where individuals search for additional cues to verify their memories (e.g., they might return to a street they grew up on). Again, no clear examples could be located where retractors explicitly mentioned doing this. The best conceptual match to this strategy was when they reported $(n=9)$

\footnotetext{
${ }^{5}$ The notion of body memories is exemplified by the work of van der Kolk (1994), and proposes that while the 'mind' forgets, the 'body' remembers. There is, as yet, no clear support for such a mechanism (Lynn, Krackow, Loftus, Locke \& Lilienfeld, 2015). Flashbacks, of course, are a key diagnostic symptom of Post-traumatic Stress Disorder. Yet, like any memories, flashbacks are subject to change and distortion (McNally, 2003). The reliability of the physical or psychological evidence that retractors reported being presented with is therefore open to question.
} 
that they had been told to search for additional cues, or evidence, that they had been abused - and this often took the form of being told to follow guidance advocated in self-help books (e.g., The Courage to Heal; Bass \& Davis, 1988).

In addition to the five strategy categories identified by Wade et al. (2014) there were two additional categories reported by retractors. These described processes of strong social influence. The first referred to the effects of medication $(n=6)$. For example, one retractor reported, “My days were filled with taking drugs that sometimes altered my ability to understand what was happening to me" (Goldstein \& Farmer, 1993, p. 228). The second category $(n=6)$ referred to changes in their immediate social context. Several examples $(n=4)$ were found where retractors reported that being hospitalized was an important precursor to the development of their beliefs and recollections about abuse (e.g., "During the next year, Doris was hospitalized 14 times"; de Rivera, 1997, p. 287).

In summary, the sources of evidence (physical, social) that people report using to try and verify moderately significant events seem to apply to high stakes events too. The key differences are that, for retractors, the evidence seems to have been presented to them, rather than being strategies they used spontaneously. Searching for 'objective' evidence was rarely mentioned. Although this latter finding might seem surprising given the potential gravity 
of coming to believe you were sexually abused, it is perhaps not surprising given the dynamics of these particular claims (i.e., as an adult there might be little hope of finding objective evidence of abuse that allegedly occurred when you were a child). Nevertheless they were sometimes presented with 'objective' physical or psychological evidence that 'confirmed' the abuse hypothesis.

Retractors reported relying on 'social' sources of evidence (e.g., asking other people) far less frequently than participants in Wade et al.'s studies. Again this is not surprising, as the specific events they were attempting to verify were ones allegedly perpetrated by the very people they might have tried to seek verification from (e.g., parents). Social sources of 'evidence' were nevertheless reported as important precursors to the repudiation of beliefs and recollections. Furthermore, retractors' reports contained many examples of the use of suboptimal 'cognitive techniques' to facilitate recall (e.g., Lynn et al., 2015). Importantly, some retractors reported that social influence tactics had been key to convincing them that they had indeed been victims of sexual abuse (e.g., the use of medication, hospitalisation).

Why did retractors attenuate belief in their recollections?

The second analysis compared the reasons given by retractors for repudiating their recollections of abuse with the reasons that participants in Scoboria et 
al.'s (2015) study gave for withdrawing or attenuating belief in their recollections. Table 3 shows the nine overarching categories derived by Scoboria et al., (2015), although their more comprehensive sub-categories were used for the initial coding (see Supplementary Material online). The middle column of Table 3 shows the number of participants in Scoboria et al.'s (2015) study who endorsed each of the categories. The rightmost column shows the number of exemplars of each category that could be located in the published retractor literature.

--Table 3 about here--

Scoboria et al. (2015) found that social feedback, followed by (a lack of) event plausibility were the most frequently reported reasons why participants in their study reported attenuating belief in a memory. Looking at the retractor literature, social feedback played a key role and, although external evidence seemed to be the largest category, the search for (dis)confirming physical evidence was rare $(n=3)$. For example, de Rivera (2000, p. 382) noted one retractor who reported that the, "Memories in hypnosis did not match scars on body". More common $(n=39)$ was that retractors encountered external evidence in the form of newspaper or magazine articles that raised questions about, or were critical of, the kinds of experiences they had had. Others explicitly sought out evidence. For example, one retractor reported that she “took a psychology class and read about 'cognitive dissonance' and ... bought 
a book ... which helped [her] to understand the way memory really works" (Ost, 2000, p. 120).

As far as social feedback was concerned, in the majority of cases $(n=22)$, this was related to the behaviour of their current therapist ("too dogmatic or was inconsistent"; de Rivera, 2000, p. 382). The remainder of reports in this category $(n=9)$ could be described as cases where retractors were told directly (by a friend or new therapist) that the events did not occur, or it was suggested to them that the events were unlikely to have happened. As noted, there was little evidence that retractors withdrew belief because the event they remembered lacked plausibility perhaps because, as noted, sexual abuse is known to be a common and under-reported crime (indeed Pezdek, Blandon-Gitlin, Lam, Hart \& Schooler, 2006, and Rubin \& Boals, 2010, provide evidence that unremembered sexual abuse is considered to be plausible by a sizeable proportion of the population). The few examples that did fall into this category $(n=3)$ are best described as cases where, "the memories became more and more bizarre" (Ost, 2000, p. 119).

Scoboria et al. (2015) also report examples where belief had been withdrawn because the recollections did not 'feel like' other memories. There were a few examples $(n=4)$ of this sort in the retractors' data. For example, one retractor wrote, “It didn't feel like regular memories to me. Certain aspects of the memories I knew were real ... but these were pieced together haphazardly, 
interwoven into a scene of sexual abuse that didn't feel real" (Lief \& Fetkewicz, 1995, p. 427). In other cases they, "figured out ... that everything had been a figment of my imagination" (Goldstein \& Farmer, 1993, p. 279) or realised that they had made a source misattribution (Lindsay, 2008) by tracing their visualizations to particular books or films (e.g., Pendergrast, 1996, p. 364; see also Heaton \& Wilson, 1998).

--Table 4 about here--

In addition to the categories provided by Scoboria et al. (2015), two new categories (and subcategories) emerged from the present data. As shown in Table 4, the largest category $(n=19)$ consisted of cases where retractors reported that a change in context (location, social situation, counselling or treatment) prompted them to question their memories ("The longer I stayed out of therapy, the more I started seeing it for what it was. The voices started disappearing from my head, that was a biggie"; Pendergrast, 1996, p. 384). A smaller category $(n=4)$ consisted of cases where either they, or someone they knew, noticed deterioration in their health (" ... a lot of good friends ... said, 'You're looking like shit, not making any sense, what are you doing?'"; Pendergrast, 1996, p. 384). Whilst this latter category might, arguably, be subsumed under Scoboria et al.'s (2015) category of social feedback, it was retained as a separate category for present purposes because the social 
feedback was not directly related to the recollection, rather the person's ongoing deterioration.

In summary, the most frequently endorsed reason for withdrawing belief that appeared in retractors' accounts related to external evidence, generally in the form of media reports that highlighted the possibility that people could misremember sexual abuse. Social feedback was the next most frequently endorsed reason for withdrawing belief, mostly as a result of inconsistent behaviour on the part of the person treating them. As with the verification strategies, a change of context (e.g., discontinuing or changing therapy or medication) was mentioned by a reasonable number of retractors as having an impact on their beliefs or recollections of abuse (see also de Rivera's 1997 discussion of the 'mind control' account, pp. 171-2). Having established that retractors' reports of the reasons they withdrew belief in their recollections matches fairly closely to the reasons for attenuating belief identified in the NBM literature (Scoboria et al., 2015) we now move to the third question. Does the definition of NBM accurately capture retractors' experiences?

Do retractors' descriptions of their recollections look like non-believed memories?

--Table 5 about here-- 
Recall that NBMs studied in the laboratory or with undergraduate samples are characterised as mental representations that have a strong recollective quality, but where the belief in occurrence has been attenuated. Do retractors' descriptions of their now retracted abuse memories have those same qualities? In fact, as shown in Table 5, it was possible to find descriptions of all possible combinations of belief and memory in retractors' accounts, not just cases where there was a recollection accompanied by a stated lack of belief. For example, there was a case where a retractor reported that they never 'recalled' anything, but was 'playing with the idea' that she had been abused (uncertain belief and no recollection; de Rivera, 1997, p. 284). In another case, there were no recollections, but a strong belief that abuse had occurred at a young age (belief but no recollection; Pendergrast, 1996, p. 367), and in another vivid 'visions' of abuse that seemed so real (belief plus recollection; presumably a report of a recollection, pre-retraction; Pendergrast, 1996, pp. 353-4). There were also cases that met the criteria for NBM where, despite rejecting the belief that she had been abused, an individual still experienced intrusive imagery (no belief, recollection; McElroy \& Keck, 1995, p. 733). Finally, there was the case reported in Ost and Nunkoosing (2010) where the recollections were reported as being contingent on the individual's illness. She reported that she only had recollections when she was ill, and did not experience them now she was 'better' (no belief, uncertain about recollections). 
What these different examples illustrate is that retractors' experiences do not fit neatly into the category of a non-believed memory ( $c f$. Scoboria et al., in press). It also suggests the primacy of belief as a precursor to (false) recollection (Scoboria et al., 2004). While there were cases where recollection occurred without belief, this was only found after the beliefs about abuse had been rejected. No examples were found where an individual had a vivid recollection of abuse that they actively rejected for a long time, before becoming convinced of the 'truth' of the recollection ${ }^{6}$ - the recollection seemed to follow the belief (for important work on the related topic of false denials, see Otgaar, Howe, Smeets \& Wang, in press).

\section{CONCLUSIONS AND WIDER IMPLICATIONS}

The key findings of this conceptual and empirical analysis were that the strategies identified in the memory verification literature and the categories proposed in the non-believed memories literatures had parallels in the limited literature on retractors' experiences. Thus the sources of evidence used to attempt to verify, or to attenuate belief in, moderately upsetting events also apply to high stakes, consequential events like sexual abuse. Perhaps this is not surprising as there are, in principle, only so many ways of establishing the truth of any given recollection - that is unlikely to change as a function of the

\footnotetext{
${ }^{6}$ Although this scenario might be more common in cases where a long-held memory is suddenly recognized as an episode of abuse once the individual acquires an understanding of sexual behavior (e.g., reaches puberty, receives sex education classes at school; see McNally \& Geraerts, 2009)
} 
seriousness of the event in question. Nevertheless there were also some noteworthy differences.

Firstly, retractors' reports contained many examples where they were exposed to sources of evidence rather than using such evidence strategically or spontaneously to verify their beliefs or recollections. It is not possible to determine, of course, whether this is a fair characterisation, or whether it is an attempt to resolve the dissonance of repudiating such a consequential set of beliefs or recollections. In other words, one way to explain how you could have come to believe in traumatic events that you now believe did not happen to you is to emphasise the coercive and non-voluntary nature of the context in which those beliefs originally arose (see Gudjonsson, 1997; Ost et al., 2001). Also, as previously noted, the conceptual comparison is not perfect, as being exposed to evidence is very different from the ways in which people report that they would strategically seek out evidence to verify their memories (Wade \& Garry, 2005; Wade et al., 2014).

Secondly, changes in the wider social context seemed to be important in terms of 'verifying', as well as attenuating, retractors' beliefs (Bartlett, 1932). This may illustrate the lengths to which one might need to go to in order to persuade someone that they had been abused (if we take retractors at their word that no such abuse had occurred), and that false beliefs or recollections of consequential events (e.g., abuse) might be contingent on being immersed 
in a social environment that supports such beliefs. For retractors, or course, it is not simply the case that belief in their recollection needs to be attenuated. They also need to somehow resolve the catastrophic interpersonal dynamics of having - they now believe falsely - accused another person (usually a family member) of the most serious crimes ${ }^{7}$.

Given the gravity of both making and then repudiating such serious allegations it is perhaps not surprising that reports of social support (or social influence; Ost et al., 2001) were cited as important determinants in the endorsement, and subsequent repudiation, of their accounts. One might speculate that the immediate social context served at first to increase, and later to decrease, the personal plausibility of sexual abuse as an explanatory framework, or supported those beliefs (Scoboria et al., 2004; but see Pezdek, Blandon-Gitlin, Lam, Hart \& Schooler, 2006; Rubin \& Boals, 2010). Borrowing from the source-monitoring framework (Lindsay, 2008), one might also call this socially-situated source attribution. But just because a history of abuse might be seen as a personally plausible event, it does not mean that one would develop (false) beliefs or recollections about having been a victim of such abuse, sometimes to the detriment of one's own health (Fetkewicz et al., 2000).

\footnotetext{
${ }^{7}$ Indeed anecdotal evidence suggests that there is a subset of retractors, sometimes referred to as 'returners'. These are individuals who attempt to reestablish contact with the people they accused without ever publicly retracting (or in some cases talking about) their previous allegations.
} 
Yet in certain contexts, false beliefs, (mis)beliefs, or vacillating beliefs, may not necessarily be maladaptive (e.g., McKay \& Dennett, 2009). After spending "ten weeks in a hospital" attending multiple personality groups (Goldstein \& Farmer, 1993, pp. 388-389) it is perhaps 'locally adaptive' to endorse a (mis)belief that one indeed might have been abused in order to get support or treatment. Conversely, upon leaving such an environment, it is possible that revising one's belief is also 'locally adaptive', enabling one to distance oneself from earlier claims (i.e., "I was the victim of poor therapy"). In other words, beliefs can be context specific, and vacillate rapidly depending on the environment one is in (see also Nash, Wheeler \& Hope, 2015).

Critically, for some retractors, belief was as far as it went. They never 'recollected' sexual abuse. Others retractors did 'recollect' vivid instances of sexual abuse that they later disowned. But here, the same point applies. A recollection that serves an explanatory function for one's life at a particular time might be more likely to be endorsed / believed (Ashmore \& Brown, 2010). If one's life circumstances change, that recollection no longer serves a useful function and may cease to be believed, or attributed to another source (e.g., a result of drug-induced hallucinations). Crudely put, if you are ill, there must be a cause of that illness, and 'recollections' of abuse might provide such evidence. Conversely, if you believe that you have been the 
victim of poor counselling, then 'false' recollections may be evidence of that too ${ }^{8}$

All of this speaks to the wider point that remembering (regardless of accuracy) is an inherently social phenomenon (Bartlett, 1932; Blank, 2009; Blank, Walther \& Isemann, in press; Marsh, 2007; Newman \& Lindsay, 2009; Ost \& Costall, 2002). From that perspective, remembering is social action that serves a function (Bartlett, 1932; Hyman, 1999); 'beliefs' or 'recollections' are used to either validate one's claims to have been abused, or to have been a victim of 'false' memory or poor therapy (Ost \& Nunkoosing, 2010). More importantly, the same beliefs or recollections can serve different functions depending on the immediate context (Ost \& Nunkoosing, 2010). The fact that people can change their minds about the same set of recollections suggests that Bartlett and later theorists (e.g., Mazzoni \& Kirsch, 2002; Scoboria et al., 2004) were correct and that it is belief (whether or not it corresponds to reality) not recollection that serves as the primary driver of people's decisions about the past. This is supported by anecdotal accounts of retractors who have retracted their retractions (Hardy, 2015).

Before concluding, some notes of caution are warranted. Firstly, these findings are based on an examination of the limited research literature on retractors. One must be careful not to over-interpret these data given the

\footnotetext{
8 The phrase 'ontological gerrymandering' has been used to describe the "phenomenon of revising history to fit with current understandings" (Ashmore \& Brown, 2010, p. 24).
} 
limitations and likely biases in those original studies; some of which were conducted more than 20 years ago at the height of the 'memory wars' (see Read \& Lindsay, 2007). The likely biases in such data have been discussed at length elsewhere (see Ost et al., 2002). Secondly, these data relate to now disowned beliefs and recollections about sexual abuse. Important unanswered questions remain about how (or whether) individuals seek to verify beliefs or recollections about continuously remembered episodes of abuse, particularly when those events occurred many years previously. This is particularly important given the research detailing the substantial barriers to disclosure in cases involving allegations of sexual abuse (e.g., London, Bruck, Ceci \& Shuman, 2007). The conclusions of the current analysis are therefore best characterised as provisional and in need of more controlled and systematic work. Bearing these important caveats in mind, some tentative conclusions can nevertheless be offered.

Are retractors' recollections clear examples of high stakes, consequential nonbelieved memories (Scoboria et al., in press)? Some may be, some might not be. Some never "got" memories (Ost, 2003). As Bartlett (1932) suggested, reasoning, rather than conscious recollection, is important in inferring the "probable constituents" of one's past, and that socially-situated beliefs (or 'attitudes') then drive recollection. As Mazzoni and Kirsch (2002) noted, recollection does not necessarily follow from belief, as many people believe things happened to them that they do not consciously recollect (e.g., that they 
were fed after they were born; a possibility also formalised in Scoboria et al.'s, 2004, nested construct model). It seems that, for some retractors at least, the same may be true; their belief about the past was more important than whether they could recollect any instances of abuse (see also Nash, Wheeler \& Hope, 2015). Furthermore, social contextual factors were critical in both the endorsement, and subsequent repudiation, of their beliefs and recollections of abuse. Whether these social factors 'caused' or merely supported (or subsequently failed to support) these now disowned beliefs and recollections is impossible to establish. What is clear though is that a "recollection" is simply one additional piece of evidence that people use to make decisions about their personal history, and is neither a necessary nor sufficient source of evidence for validating or invalidating beliefs about high stakes consequential events from the past. 


\section{REFERENCES}

Ashmore, M., \& Brown, S. D. (2010). On changing one's mind twice: the strange credibility of retracting recovered memories. In J. Haaken \& P. Reavey (Eds.), Memory matters: Contexts for understanding sexual abuse recollections (pp. 17-40). Hove, UK: Routledge.

Bartlett, F. C. (1932). Remembering: A study in experimental and social psychology. Cambridge: Cambridge University Press.

Bass, E. \& Davis, L. (1988). The courage to heal: A guide for women survivors of child sexual abuse. New York: Harper and Row.

Blank, H. (2009). Remembering: A theoretical interface between memory and social psychology. Social Psychology, 40, 164-175.

Blank, H., Walther, E., \& Isemann, S. D. (in press). The past is a social construction: Susceptibility to social influence in (mis)remembering. In R. A. Nash \& J. Ost (Eds.), False and distorted memories. Hove, UK: Psychology Press.

Blume, E. S. (1995). The ownership of truth. The Journal of Psychohistory, 23, 131-140.

Davis, J. E. (2005). Victim narratives and victim selves: False Memory Syndrome and the power of accounts. Social Problems, 52, 529-548.

de Rivera, J. (1997). The construction of false memory syndrome: The experience of retractors. Psychological Inquiry, 8, 271-292.

de Rivera, J. (1998). Relinquishing believed-in imaginings: Narratives of individuals who have repudiated false accusations. In J. de Rivera \& T. R. Sarbin (Eds.), Believed-in imaginings: The narrative construction of reality (pp. 169-188).

Washington, DC: American Psychological Association. 
de Rivera, J. \& Sarbin, T. R. (1998). Believed-in imaginings: The narrative construction of reality. Washington, DC: American Psychological Association.

de Rivera, J. (2000). Understanding persons who repudiate memories recovered in therapy. Professional Psychology: Research and Practice, 31, 378-386.

Edwards, D., \& Middleton, D. (1987). Conversation and remembering: Bartlett revisited. Applied Cognitive Psychology, 1, 77-92.

Edwards, D., Potter, J., \& Middleton, D. (1992). Toward a discursive psychology of remembering. The Psychologist, 5, 441-446.

Epstein, M. A., \& Bottoms, B. L. (1998). Memories of childhood sexual abuse: A survey of young adults. Child Abuse \& Neglect, 22, 1217-1238.

Fetkewicz, J., Sharma, V., \& Merskey, H. (2000). A note on suicidal deterioration with recovered memory treatment. Journal of Affective Disorders, 58, 155-159.

Garry, M., Manning, C. G., Loftus, E. F., \& Sherman, S. J. (1996). Imagination inflation: Imagining a childhood event inflates confidence that it occurred. Psychological Bulletin and Review, 3, 208-214.

Goldstein, E., \& Farmer, K. (1993). True stories of false memories. Florida: Upton Books. Gudjonsson, G. H. (1997). False memory syndrome and the retractors. Psychological Inquiry, 8, 296-299.

Hardy, F. (2015, January 22). Did an internet predator target an innocent young girl and persuade her to falsely accuse her loving father of sexual abuse? Daily Mail. Retrieved 16.03.16 from http:// www.dailymail.co.uk/femail/article2920867/Internet-Svengali-persuaded-loving-child-falsely-accuse-fatherABUSE-Claire-claim-tear-family-apart-forever.html. 
Heaton, J. A., \& Wilson, N. L. (1998). Memory, media, and the creation of mass confusion. In S. J. Lynn \& K. M. McConkey (Eds.), Truth in memory (pp. 349371). New York: Guilford Press.

Hinde, R. A. (1999). Why gods persist: A scientific approach to religion. London: Routledge.

Hyman, I. E. (1999). Creating false autobiographical memories: Why people believe their memory errors. In E. Winograd, R. Fivush \& W. Hirst (Eds.), Ecological approaches to cognition: Essays in honor of Ulric Neisser (pp. 229-252). Mahwah, NJ: Lawrence Erlbaum Associates.

Kassin, S. M. (1997). False memories turned against the self. Psychological Inquiry, 8, 300-302.

Larsen, S. F., \& Berntsen, D. (2000). Bartlett's trilogy of memory: Reconstructing the concept of attitude. In A. Saito (Ed.), Bartlett, culture and cognition (pp. 90-114). Guildford, UK: Psychology Press.

Lief, H., \& Fetkewicz, J. (1995). Retractors of false memories: The evolution of pseudo-memories. The Journal of Psychiatry and Law, 23, 411-436.

Lindsay, D. S. (2008). Source monitoring. In H. L. Roediger, III (Ed.), Cognitive psychology of memory. Volume 2 of learning and memory: A comprehensive reference (pp. 325-348). Oxford: Elsevier.

Loftus, E. F. (1998). The price of bad memories. Skeptical Inquirer, 22, 23-24.

Loftus, E. F., \& Ketcham, K. (1991). Witness for the defense: The accused, the eyewitness, and the expert who puts memory on trial. New York: St. Martin's Press. 
Loftus, E. F. \& Pickrell, J. E. (1995). The formation of false memories. Psychiatric Annals, 25, 720-725.

London, K., Bruck, M., Ceci, S. \& Shuman, D. (2007). Disclosure of child sexual abuse: A review of the contemporary empirical literature. In Pipe, M., Lamb, M., Orbach, Y. and Cederborg, A (Eds.). Child sexual abuse: Disclosure, delay, and denial (pp. 1139). London: Erlbaum.

Lynn, S. J., Krackow, E., Loftus, E. F., Locke, T. G., \& Lilienfeld, S. O. (2015).

Constructing the past: Problematic memory recovery techniques in psychotherapy. In S. O. Lilienfeld, S. J. Lynn \& J. M. Lohr (Eds.), Science and pseudoscience in clinical psychology (2nd edition, pp. 210-244). New York: Guilford Press.

Lyon, T. D. (2007). False denials: Overcoming methodological biases in abuse disclosure research. In M-E. Pipe, M. E. Lamb, Y. Orbach \& A-C. Cederborg (Eds.), Child sexual abuse: Disclosure, delay, and denial (pp. 41-62). New York: Routledge.

Malloy, L. C., Lyon, T. D., Quas, J. A. (2007). Filial dependency and recantation of child sexual abuse. Journal of the American Academy of Child E Adolescent Psychiatry, 46, 162- 170.

Maran, M. (2010). My lie: A true story of false memory. San Francisco: Jossey-Bass.

Marsh, E. J. (2007). Retelling is not the same as recalling: Implications for memory. Current Directions in Psychological Science, 16, 16-20.

Mazzoni, G. \& Kirsch, I. (2002). Autobiographical memories and beliefs: A preliminary metacognitive model. In T. Perfect \& B. Schwartz (Eds.), Applied metacognition (pp. 121-145). Cambridge, UK: Cambridge University Press. 
Mazzoni, G., Scoboria, A., \& Harvey, L. (2010). Non-believed memories. Psychological Science, $21,1334-1340$

McElroy, S. L., \& Keck, P. E. (1995). Recovered memory therapy: False memory syndrome and other complications. Psychiatric Annals, 25, 731-735.

McKay, R. T., \& Dennett, D. C. (2009). The evolution of misbelief. Behavioral and Brain Sciences, 32, 493-561.

McNally, R. J. (2003). Remembering trauma. Harvard: Harvard University Press.

McNally, R. J., \& Geraerts, E. (2009). A new solution to the Recovered Memory Debate. Perspectives on Psychological Science, 4, 126-134.

Nash, R. A., \& Takarangi, M. K. T. (2011). Reconstructing alcohol-induced memory blackouts. Memory, 19, 566-573.

Nash, R. A., Wheeler, R. L., \& Hope, L. (2015). On the persuadability of memory: Is changing people's memories no more than changing their minds? British Journal of Psychology, 106, 308-326.

Nelson, E. L., \& Simpson, P. (1994). First glimpse: An initial examination of subjects who have rejected their recovered visualizations as false memories. Issues in Child Abuse Accusations, 6, 123-133.

Newman, E. J., \& Lindsay, D. S. (2009). False memories: What the hell are they for? Applied Cognitive Psychology, 23, 1105-1121.

Ost, J. (2000). Recovering memories: Convergent approaches toward an understanding of the false memory debate. Unpublished doctoral thesis. University of Portsmouth: Portsmouth, UK. 
Ost, J. (2003). Seeking the middle ground in the 'memory wars'. British Journal of Psychology, 94, 125-139.

Ost, J., \& Costall, A. (2002). Misremembering Bartlett: a study in serial reproduction. British Journal of Psychology, 93, 243-255.

Ost, J., Costall, A. \& Bull, R. (2001). False confessions and false memories? A model for understanding retractors' experiences? The Journal of Forensic Psychiatry, $12,551-581$.

Ost, J., Costall, A. \& Bull, R. (2002). A perfect symmetry? A study of retractors' experiences of making and then repudiating claims of early sexual abuse. Psychology, Crime E Law, 8, 155-181.

Ost, J., \& Nunkoosing, K. (2010). Reconstructing Bartlett and revisiting the 'false memory' controversy. In J. Haaken \& P. Reavey (Eds.), Memory matters: understanding contexts for recollecting child sexual abuse (pp. 41-62). Hove, UK: Routledge.

Otgaar, H., Howe, M.L., Smeets, T., \& Wang, J. (in press). Denial-induced forgetting: False denials undermine memory, but external denials undermine belief. Journal of Applied Research in Memory and Cognition.

Otgaar, H., Scoboria, A., \& Smeets, T. (2013). Experimentally evoking nonbelieved memories for childhood events. Journal of Experimental Psychology: Learning, Memory and Cognition, 39, 717-730.

Pendergrast, M. (1996). Victims of memory: Incest accusations and shattered lives (2nd edition). Hinesburg, VT: Upper Access, Inc. 
Pezdek, K., Blandon-Gitlin, I., Lam, S., Hart, R.E. \& Schooler, J. (2006). Is knowing believing? The role of event plausibility and background knowledge in planting false beliefs about the personal past. Memory $\mathcal{E}$ Cognition. 34, 16281635.

Read, J. D., \& Lindsay, D. S. (1997). Recollections of trauma: Scientific evidence and clinical practice. New York: Plenum Press.

Rubin, D. C., \& Boals, A. (2010). People who expect to enter psychotherapy are prone to believing that they have forgotten memories of childhood trauma and abuse. Memory, 18, 556-562.

Schacter, D. L., Norman, K. A. \& Koutstaal, W. (1997). The recovered memories debate: A cognitive neuroscience perspective. In M. A. Conway (Ed.), Recovered memories and false memories (pp. 63-99). Oxford: Oxford University Press.

Schooler, J. W., Bendiksen, M. \& Ambadar, Z. (1997). Taking the middle line: Can we accommodate both fabricated and recovered memories of sexual abuse? In M. A. Conway (Ed.), Recovered memories and false memories (pp. 251-292). Oxford: Oxford University Press.

Scoboria, A., Boucher, C., \& Mazzoni, G. (2015). Reasons for withdrawing belief in vivid autobiographical memories. Memory, 23, 545-562.

Scoboria, A., Mazzoni, G., \& Boucher, C., (in press). Nonbelieved memories: A review of findings and theoretical implications. In R. A. Nash \& J. Ost (Eds.), False and distorted memories. Hove, UK: Psychology Press. 
Scoboria, A., Mazzoni, G., Kirsch, I. \& Relyea, M. (2004). Plausibility and belief in autobiographical memory. Applied Cognitive Psychology, 18, 791-807.

Singer, J. (1997). How recovered memory debates reduce the richness of human identity. Psychological Inquiry, 8, 325-329.

van der Kolk, B. A. (1994). The body keeps the score: Memory and the evolving psychobiology of posttraumatic stress. Harvard Review of Psychiatry, 1, 253-265.

Wade, K. A., \& Garry, M. (2005). Strategies for verifying false autobiographical memories. American Journal of Psychology, 118, 587-602.

Wade, K. A., Nash, R. A., \& Garry, M. (2014). People consider reliability and cost when verifying their autobiographical memories. Acta Psychologica, 146, 28-34.

Wilson, A. E., \& Ross, M. (2003). The identity function of autobiographical memory: Time is on our side. Memory, 11, 137-149.

Woodiwiss, J. (2010). 'Alternative memories' and the construction of a sexual abuse narrative. In J. Haaken \& P. Reavey (Eds.), Memory matters: Understanding contexts for recollecting child sexual abuse (pp. 105-127). London: Routledge. 
Table 1. Conceptual mapping of Wade et al.'s (2014) strategies to conceptually related sources of evidence used to 'verify' retractors' recollections or beliefs.

\section{Strategies (from Wade et al., 2014)}

\begin{tabular}{ll}
\hline Search for physical evidence & $\begin{array}{l}\text { Presented with 'physical' or 'psychological' } \\
\text { evidence }\end{array}$ \\
\hline Asking another person - family & Being told by another person - family \\
\hline Asking another person - other & Being told by another person - other \\
\hline Cognitive techniques & Memory recovery techniques \\
\hline Searching for additional cues & $\begin{array}{l}\text { Told to search for additional cues / self help } \\
\text { books }\end{array}$ \\
\cline { 2 - 2 } & Other - medication \\
\cline { 2 - 2 } & Other - change of context
\end{tabular}

Exemplar

Interpreting 'body memory' [choking] as indicative of abuse (Pendergrast, 1996, p. 378)

For some reason my ex-husband is convinced now that my dad did abuse me (Ost \& Nunkoosing, 2010, pp. 24-25) Therapist kept telling her that he father had sexually abused her (de Rivera, 1997, p. 286) Instructed to draw pictures of anything that came to mind, free association (McElroy \& Keck, 1995, p. 732)

Encouraged to read The Courage to Heal (Pendergrast, 1996, p. 381)

My days were filled with taking drugs that sometimes altered my ability to understand what was happening to me (Goldstein \& Farmer, 1993, p. 228)

Ten weeks in hospital ... attended MPD (multiple personality disorder) group (Goldstein \& Farmer, 1993, pp. 388-389)

Note: Wade et al.'s (2014) categories in bold font, conceptually related source of evidence reported in the retractor literature in italics. 
Table 2. Sources of evidence - comparison of Wade et al.'s (2014) categories and retractor literature.

Wade et al. (2014)*

Retractors literature

Evidence consulted (from Wade et al., 2014)

\begin{tabular}{|c|c|c|c|}
\hline & & \multicolumn{2}{|c|}{ Conceptually related source of evidence in retractor literature } \\
\hline$N$ & 1105 & & $56 * *$ \\
\hline \multirow[t]{2}{*}{ Search for physical evidence } & $37.5 \%$ & \multirow[b]{2}{*}{ Presented with 'physical' or 'psychological' evidence } & -- \\
\hline & -- & & $(14 \%)$ \\
\hline \multirow[t]{2}{*}{ Asking another person - family } & $27.0 \%$ & \multirow[b]{2}{*}{ Being told by another person - family } & - \\
\hline & -- & & $(3.5 \%)$ \\
\hline \multirow[t]{2}{*}{ Asking another person - other } & $26.2 \%$ & \multirow[b]{2}{*}{ Being told by another person - other } & -- \\
\hline & -- & & $(16 \%)$ \\
\hline \multirow[t]{2}{*}{ Cognitive techniques } & $3.5 \%$ & \multirow[b]{2}{*}{ Memory recovery techniques } & $7 \%$ \\
\hline & -- & & $(23 \%)$ \\
\hline \multirow[t]{4}{*}{ Searching for additional cues } & $5.9 \%$ & \multirow[b]{2}{*}{ Told to search for additional cues / self help books } & -- \\
\hline & -- & & $(16 \%)$ \\
\hline & -- & Other-medication & $(10 \%)$ \\
\hline & -- & Other - change of context & $(10 \%)$ \\
\hline
\end{tabular}

Notes: Wade et al.'s (2014) categories in bold font, conceptually related strategies from the retractor literature in italics. * Percentages taken from p. 30 of Wade et al. (2014). ${ }^{* *}$ The total number of individual descriptions that could be found in the retractor literature (see supplementary materials). 
Table 3. Reason for attenuating belief in memory - comparison of Scoboria et al.'s (2015) categories and retractor literature.

\begin{tabular}{lcccc} 
& $\begin{array}{c}\text { Scoboria et al. } \\
(2015)^{*}\end{array}$ & \multicolumn{2}{c}{$\begin{array}{c}\text { Retractors } \\
\text { literature ** }\end{array}$} \\
\hline$N$ & \multicolumn{2}{c}{374} & \multicolumn{2}{c}{$\sim 158^{* * *}$} \\
\hline Social feedback (12 sub categories) & $\mathbf{1 5 8}$ & $(42.2 \%)$ & $\mathbf{3 1}$ & $(19.6 \%)$ \\
Event plausibility (2 sub categories) & 73 & $(19.5 \%)$ & $\mathbf{3}$ & $(1.8 \%)$ \\
Alternative attributions (4 sub categories) & $\mathbf{3 3}$ & $(8.8 \%)$ & $\mathbf{2}$ & $(1.2 \%)$ \\
General beliefs re: memory (3 sub categories) & $\mathbf{2 4}$ & $(6.4 \%)$ & $\mathbf{1}$ & $(0.6 \%)$ \\
Internal memorial characteristics & $\mathbf{2 7}$ & $(7.2 \%)$ & $\mathbf{4}$ & $(2.5 \%)$ \\
Notions of self / others (2 sub categories) & $\mathbf{2 4}$ & $(6.4 \%)$ & $\mathbf{0}$ & $(0.0 \%)$ \\
External (2 sub categories) & $\mathbf{2 7}$ & $(7.2 \%)$ & $\mathbf{4 3}$ & $(27.2 \%)$ \\
Personal motivation & $\mathbf{4}$ & $(1.1 \%)$ & $\mathbf{3}$ & $(1.8 \%)$ \\
Other & $\mathbf{4}$ & $(1.1 \%)$ & $\mathbf{2}$ & $(1.2 \%)$
\end{tabular}

Notes: * Taken from Table 2, column 3 of Scoboria et al. $(2015$, p. 8$)$ and refers to the category judged as the 'primary' reason for attenuating belief. ** Reasons do not sum to 158 because, in some cases, nothing is explicitly mentioned about what motivated the retraction (e.g. Lief \& Fetkewicz, 1995). *** Likely duplicates across studies - obvious cases only coded once (e.g., Laura Pasley, Beth Rutherford). 
Table 4. New categories of reason for attenuating belief in memory.

\begin{tabular}{|c|c|c|}
\hline $\begin{array}{l}\text { New categories (and } \\
\text { subcategories) }\end{array}$ & $\mathrm{n}$ & Exemplar \\
\hline Change of context & 19 & \\
\hline $\begin{array}{r}\text { Change of therapy (no } \\
\text { direct questioning) }\end{array}$ & 3 & $\begin{array}{l}\text { "At this [new] hospital I gained a new outlook and began } \\
\text { to trust my own intuitions" (Goldstein \& Farmer, } 1993 \text { p. } \\
\text { 230) }\end{array}$ \\
\hline $\begin{array}{l}\text { Leaving therapy } \\
\text { (voluntary) }\end{array}$ & 6 & $\begin{array}{l}\text { "Within two weeks of leaving therapy I realized that my } \\
\text { memories were false" (Nelson \& Simpson, 1994, p. 125) }\end{array}$ \\
\hline $\begin{array}{l}\text { Leaving therapy } \\
\text { (involuntary) }\end{array}$ & 2 & $\begin{array}{l}\text { "Ran out of money, kicked out [of therapy] cold turkey, } \\
\text { praise God!" (Lief \& Fetkewicz, 1995, p. 426) }\end{array}$ \\
\hline Stopping medication & 7 & $\begin{array}{l}\text { "I also lowered my medications so that I could think } \\
\text { more clearly and went off a medication that affects } \\
\text { memory" (Ost, 2000, p. 120) }\end{array}$ \\
\hline Isolated from family & 1 & $\begin{array}{l}\text { “... after only } 4 \text { days, Ann missed her children and } \\
\text { husband so much that she changed her ticket and flew } \\
\text { home" (de Rivera, 1997, p. 278) }\end{array}$ \\
\hline $\begin{array}{l}\text { Noticing } \\
\text { deterioration }\end{array}$ & 4 & \\
\hline Noticed themselves & 2 & $\begin{array}{l}\text { "By } 1990 \text { I'd been following the instructions in The } \\
\text { Courage to Heal for two years, with negligible results. I } \\
\text { decided to try a different way to heal" (Maran, 2010, p. } \\
\text { 132) }\end{array}$ \\
\hline Noticed by others & 2 & $\begin{array}{l}\text { [Friends] “said, 'You're looking like shit, not making any } \\
\text { sense, what are you doing?'” (Pendergrast, 1996, p. 384) }\end{array}$ \\
\hline
\end{tabular}


Table 5. Combinations of memory and belief evidenced in retractors' accounts.

\section{'Belief' 'Memory' Example}

? No "At this point, the investigator remarked, 'It doesn't sound like you ever really had memories of being abused. It sounds like you were kind of playing with the idea of being abused," (de Rivera, 1997, p. 284).

Yes No "I never developed any specific times and places, but I was sure the abuse had occurred on a continual basis between the ages of 5 and 15" (Pendergrast, 1996, p. 367)

Yes Yes "The visions in my head were of severe physical and sexual abuse. The images were so incredibly bizarre but seemed so real" (Pendergrast, 1996, pp. 353-4).

No Yes "Ms. B continues to experience the intrusion of false memories approximately once per month..." (McElroy \& Keck, 1995, p. 733)

No ? “... the memories that I had when I was ill, although I ... certainly can't remember them anyway. I mean I remember when ... I was ill. I could tell you [in] huge, vivid graphic detail all of this, I wouldn't even be able to do that now" (Ost \& Nunkoosing, 2010, p. 29) 